\title{
ÓXIDOS DE FERRO E DE ALUMÍNIO E A MINERALOGIA DA FRAÇÃO ARGILA DEFERRIFICADA DE LATOSSOLOS ÁCRICOS ${ }^{1}$
}

\author{
L.R.F. ALLEONI; ; O.A. CAMARGO ${ }^{3,4}$ \\ ${ }^{2}$ Estação Experimental de Piracicaba-IAC, C.P. 28, CEP: 13400-970 - Piracicaba,SP. \\ ${ }^{3}$ Instituto Agronómico de Campinas, C.P. 28, CEP: 13001-970 Campinas, SP. \\ Bolsista do CNPq.
}

\begin{abstract}
RESUMO: Foram obtidos os teores totais e também os livres e amorfos de óxidos de ferro e aluminio de dois latossolos roxos (LR) e de um latossolo variação Una (LU) ácricos do norte do Estado de Sảo Paulo, que se caracterizam por avançado estado de intemperismo, exibindo CTC efetiva menor que $15 \mathrm{mmolc} / \mathrm{kg}$ de argila. Para os três solos, a mineralogia da fraçảo argila fol dominada por caulinita e gibbsita, aparecendo também vermiculita com hidroxila entrecamadas em pequena quantidade. Nos latossolos roxos ácricos, os teores de ferro e alumínio totais, livres e amorfos foram maiores do que no LU. Nesses solos, a gibbsita respondeu por mais da metade da fração argila deferrificada, enquanto que no LU a participaçāo da caulinita fol mais significativa (54 $\times 46 \%$ ). No latossolo variaçāo Una, que apresenta coloração amarelada, as formas de alumínio extraidas com ditionito responderam por uma porcentagem maior do alumínio total (25\%) do que nos LRs (13\%, em média), sendo que a relação superficie específica/ Fe livre foi maior do que nos latossolos roxos.

Descritores: mineralogia de argila, 6xidos de ferro e alumínio, latossolos ácricos
\end{abstract}

\section{IRON AND ALUMINIUM OXIDES AND THE MINERALOGY OF IRON FREE CLAY FRACTION OF ACRIC OXISOLS}

SUMMARY: Total, free and amorphous iron and aluminium oxides were obtained from three acric Oxisols (two dusky-red latosol - LR and one Una variant latosol - LU) from the State of São Paulo, Brazil. These soils are in an advanced stage of weathering, having an effective CEC lower than $15 \mathrm{mmolc} / \mathrm{kg}$ clay. For all solls, the clay mineralogy was dominated by kaolinite and gibbsite, showing also some peaks of hidroxy-interlayered vermiculite. The $L R$ had total, free and amorphous iron and aluminium contents higher than in the LU. In those soils, gibbsite represented more than $50 \%$ of iron free clay fraction of the $B_{w}$ horizon, while in the $L U$ the participation of kaolinite was higher $(54 \% \times 46 \%)$. In the Una variant latosol, with more intense yellow color, free aluminium represented $25 \%$ of the total, while in the LR it was $13 \%$. The ratio specific surface area/free Fe-oxide was higher in the LU than in the dusky-red ones.

Key Words: clay mineralogy, imon and aluminium oxides, acric Orisols

\section{INTRODUÇÃO}

Solos em avançado estado de intemperismo apresentam intensa perda de sílica (dessilicatização), com resultante acúmulo de óxidos insolúveis de ferro e alumínio (UEHARA, 1988), sendo os mais freqüentes a goetita $(\alpha \mathrm{FeOOH})$, a hematita $\left(\alpha_{F e} \mathrm{O}_{3}\right)$ e a gibbsita $\mathrm{\gamma Al}(\mathrm{OH})_{3}$. De acordo com KÄMPF et al. (1988), a primeira confere cor amarela ao solo $(2,5 Y-10 Y R)$ na ausência de hematita, enquanto, na segunda, a cor $E$ avermelhada $(2,5 Y R$ - 5R), mesmo quando ela aparece em pequenas quantidades. Os 6́xidos de ferro e alumínio exercem marcante influência nos atributos eletroquímicos de solos altamente intemperizados dos trópicos. NASCIMENTO et al. (1988) e ALLEONI \& CAMARGO (1994a) obtiveram alta correlação negativa entre os índices ki e kr (que diminuem com o teor de óxidos) e o ponto de carga zero (pcz) de latossolos brasileiros. Quanto mais efetiva a participação destes óxidos na definição do balanço de cargas do solo, maior deve ser o pcz, principalmente nos horizontes subsuperficiais, já que o pcz dos ́xidos é alto (entre 7,5 e 9,0), e o efeito da matéria orgânica é menor (SAKURAI et al., 1989). A quantificação dos teores

\footnotetext{
1 Parte da Dissertação de Mestrado do primeiro autor apresentado à ESALQ/USP.
} 
de ferro e alumínio é importante taxonomicamente, pois o grande grupo acric da classificação americana contempla solos ricos em minerais de ferro, enquanto no grande grupo gibbsic estão os solos ricos em minerais de alumínio (ESWARAN \& TAVERNIER, 1980).

Além dos teores totais dos 6́xidos, é importante conhecer a quantidade de óxidos livres, pois a relação óxido de $\mathrm{Fe}$ ou Al livre/óxido total exprime a evolução do elemento no solo e evidencia, entre outros fatores, o grau de intemperismo do solo (MELO \& JOHAS, 1988). Outro atributo é o teor de óxidos amorfos, que dá idéia do grau de cristalinidade do composto. Quanto menor a relação óxido amorfo/óxido total, maior o predomínio das formas bem cristalizadas do óxido (KÄMPF et al., 1988).

No extremo da escala de intemperismo aparecem os solos ácricos, que possuem, por definição, uma capacidade de troca de cátions efetiva menor que $15 \mathrm{mmolc} / \mathrm{kg}$ de argila, numa profundidade de ate $150 \mathrm{~cm}$ (SOIL SURVEY STAFF, 1990). Estes solos aparecem em paisagens antigas do ambiente tropical, sendo normalmente profundos e friáveis. Em levantamentos de solos do Estado de São Paulo, realizados pelo Instituto Agronômico de Campinas, foram contabilizados mais de $\mathbf{7 4 . 0 0 0}$ hectares de solos ácricos (sozinhos ou associados) na região de Ribeirão Preto (OLIVEIRA \& PRADO, 1987) e 95.000 hectares destes solos nas proximidades de Guaíra (OLIVEIRA \& PRADO, 1994). Ambas as regiões do norte do Estado possuem agricultura de alto nível tecnolbgico e solos com teores de ferro elevados, grande parte acima de $200 \mathrm{~g} / \mathrm{kg}$.

$O$ objetivo deste trabalho foi quantificar os teores de óxidos de ferro e alumínio (totais, livres e amorfos) e apresentar a análise mineralógica quantitativa e qualitativa de amostras de argila deferrificada do horizonte $B_{\text {w }}$ de três latossolos ácricos do Estado de São Paulo, comparando os resultados com os de outros autores que também estudaram amostras de oxissolos altamente intemperizados.

\section{MATERIAL E MÉTODOS}

Coletaram-se amostras dos horizontes A $(0-20 \mathrm{~cm})$ e $B_{w}$ (na maior expressão do perfil) de latossolos ácricos, assim discriminados: latossolo roxo ácrico, localizado em Ribeirão Preto,SP (LRác $)$; latossolo roxo ácrico, de Guaíra,SP
(LRác $c_{2}$ ) e latossolo variação Una ácrico, de Guaíra, SP (LUác). Este último solo, que normalmente aparece em cotas intermediárias do relevo, apresenta drenagem deficiente, com redução do $\mathrm{Fe} e$ presença de matizes mais amareladas do que 4YR (OLIVEIRA et al., 1991). Maiores detalhes das análises químicas e físicas dos solos podem ser encontrados em ALLEONI \& CAMARGO (1994ab). Teores totais de $\mathrm{Fe}_{2} \mathrm{O}_{3}$ e $\mathrm{Al}_{2} \mathrm{O}_{3}\left(\mathrm{Fe}_{\mathrm{t}}\right.$ e $\left.\mathrm{Al}_{\mathrm{t}}\right)$ foram obtidos após ataque sulfúrico; ferro e alumínio livres $\left(\mathrm{Fe}_{\mathrm{d}}\right.$ e $\mathrm{Al}_{\mathrm{d}}$, foram assim determinados: em meio tamponado (bicarbonato $\mathrm{pH} \mathrm{7,3),} \mathrm{ferro} \mathrm{e} \mathrm{alumínio}$ foram reduzidos pelo ditionito de sódio e complexados por citrato de sódio, permanecendo em solução; teores de ferro e alumínio amorfos $\left(\mathrm{Fe}_{\mathrm{o}}\right.$ e $\mathrm{Al} \mathrm{l}_{\mathrm{o}}$ ) foram obtidos por solubilização do ferro ou do alumínio amorfos em ácido oxálico e seu sal de amônio.

A análise mineralógica qualitativa foi realizada na Seção de Pedologia do Instituto Agronômico de Campinas, em amostras de argila previamente tratadas para eliminação de matéria orgânica (com água oxigenada) e óxidos de ferro (com duas extrações de ditionito - citrato - bicarbonato de sódio) e auxílio da difração de raios $\mathrm{X}$ nas amostras saturadas com $\mathrm{Mg}$, glicoladas, e nas saturadas com $\mathrm{K}$ e submetidas às temperaturas de 25,350 e $550^{\circ} \mathrm{C}$. Caulinita e gibbsita foram quantificadas no Laboratório de Mineralogia do Departamento de Ciência do Solo da ESALQ/USP, por meio de análise térmica diferencial (ATD) em amostras de argila deferrificada, isentas de matéria orgânica e saturadas com $\mathrm{Mg}$. As amostras foram misturadas com $\mathrm{Al}_{2} \mathrm{O}_{3}$ calcinado, na proporção de 1:3 para o LUác e 1:7 para os LRác.

\section{RESULTADOS E DISCUSSÃO}

Teores de 6xidos - Na TABELA 1 encontram-se os teores de ferro e alumínio totais, livres e amorfos. Em relação ao ferro, nota-se que os teores totais foram elevados para os latossolos roxos ( $>260 \mathrm{~g}$ ) $\mathrm{kg}$ ) e bem menores para o LUác ( $<100 \mathrm{~g} / \mathrm{kg}$ ). Os teores de ferro livre (Fed) foram também maiores para os LRs, sendo que esta forma representou mais da metade do ferro total (média de $53 \%$ ), tanto para os latossolos roxos, como para o latossolo variação Una. Esta quantidade foi inferior à encontrada por VETTORI (1969), para quem o ferro livre deveria representar cerca de $90 \%$ do total. Entretanto, KÄMPF et al. (1988) citam que a diferença entre Fed e Fet aumenta em solos 
TABELA 1 - Teores de ferro e alumínio totais (Fet e Alt), livres (Fed e Ald) e amorfos (Feo e Alo), e relação superfície específica (SE) / Fe livre (Fed) de latossolos ácricos paulistas.

\begin{tabular}{|c|c|c|c|c|c|c|c|c|}
\hline$\overline{\text { Solo }}$ & Camada & Fet & Fed & Feo & Alt & Ald & Alo & SE/Fed \\
\hline & $\mathbf{c m}$ & \multicolumn{7}{|c|}{$\mathrm{g} / \mathrm{kg}-\mathrm{m}^{2} / \mathrm{g}$} \\
\hline LRácl & $0-20$ & 320 & 164 & 13 & 195 & 26 & 10 & 460 \\
\hline LRác1 & $80-100$ & 341 & 185 & 9 & 195 & 21 & 7 & 260 \\
\hline LRác2 & $0-20$ & 256 & 143 & 15 & 223 & 31 & 8 & 730 \\
\hline LRác2 & $100-150$ & 270 & 143 & 14 & 223 & 34 & 10 & 500 \\
\hline LUác & $0-20$ & 66 & 39 & 2 & 91 & 22 & 6 & 1080 \\
\hline LUác & $40-60$ & 96 & 45 & 2 & 125 & 31 & 8 & 1440 \\
\hline
\end{tabular}

LRác1 = latossolo roxo ácrico de Ribeirão Preto (SP); LRác2 = latossolo roxo ácrico de Guaíra (SP); LUác = latossolo variação Una ácrico.

derivados de rochas básicas, devido à presença de minerais primários, como a magnetita e a ilmenita, que não são extraídos pelo ditionito e citrato de sódio. Desse modo, os resultados obtidos parecem coerentes, pois estes solos ácricos são originados de basalto. Alem disso, é possível que as duas extrações com ditionito não tenham sido suficientes para extrair todo o ferro, mesmo que, visualmente, não se notasse necessidade de extrações adicionais.

Os maiores teores de Fe total dos LRác, em relação ao LUác, eram esperados e corroboram os dados de OLIVEIRA et al. (1991), que estudaram LUs localizados próximos aos locais de onde foram coletadas as amostras para este trabalho. Segundo estes autores, os teores de Fe tendem a ser decrescentes declive abaixo, indicando condições favoráveis à sua exportação, com formação de plintita, petroplintita ou bancada laterítica em cotas mais inferiores.

Para o alumínio, as formas livres nos latossolos roxos variaram de 11 a $15 \%$ quando comparadas ao total, enquanto o LUác apresentou valores maiores ( $24 \%$ na camada superficial e $25 \%$ no horizonte B). CURI \& FRANZMEIER (1984) também constataram maior extração de alumínio pelo ditionito em solos mais amarelados e observaram que o maior teor de alumínio livre pode ter efeito no maior poder adsortivo e menor poder dessortivo de fosfato que estes solos têm, em relação aos mais avermelhados. Para o Al amorfo, em comparação com o Al total, os valores percentuais no LUác foram um pouco superiores $(6 \%$ e $7 \%)$ do que os demais (4\% e $5 \%$ ).

As formas livres (Fed e Ald) predominaram sobre as amorfas (TABELA 1). A relação $\mathrm{Feo} / \mathrm{Fed}$ variou de 0,05 a 0,1 , enquanto que a relação Alo/Ald esteve ao redor de 0,3 , valores próximos aos obtidos por POMBO et al. (1982), em um latossolo roxo gaúcho. SAKURAI et al. (1989) a firmam que o elevado intemperismo em ambientes tropicais promove cristalização dos oxidos de ferro e alumínio, resultando em baixas relações entre as formas amorfas e cristalinas, que variaram de 0,03 a 0,3 para solos cauliníticos do Japão. KÄMPF et al. (1988) também obtiveram valores de Feo/Fed nesta faixa, para oxissolos do sul e sudeste brasileims, o que vem confirmar os dados do presente estudo.

Relaçăo superficie especfifica/Fe livre - Segundo CURI \& FRANZMEIER (1984), não há relação entre a superfície específica (SE) de um solo e sua posição numa topossequiência. Entretanto, grande parte da SE pode ser devida aos óxidos, de modo que a relação superfície especifica e Fe livre pode ser significativa. Tomando-se as SEs de latossolos ácricos coletados no mesmo local das amostras deste trabalho, cujos valores são apresentados em ALLEONI \& CAMARGO $(1994$, c), e dividindoos pelos teores de ferro livre, observa-se que tanto em superfície, como em subsuperfície, o LUác apresentou relações superiores às dos latossolos roxos, o que está de acordo com CURI \& FRANZMEIER (1984), que notaram aumento nesta relação, indo de solos mais vermelhos com hematita para solos mais amarelos com alto teor de goetita.

And́lises mineralogicas - Nas figuras 1, 2 e 3 estão os difratogramas de raios $X$, e na figura 4 aparecem as curvas de análise térmica diferencial da argila deferrificada dos horizontes subsuperficiais dos 
latossolos ácricos.

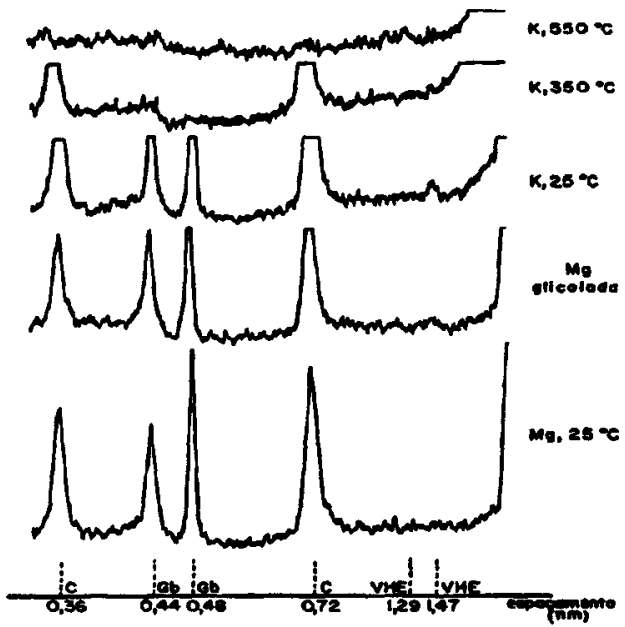

Figura 1 - Difratogramas de raios $X$ da fração argila deferrificada de horizonte $B$ do latossolo roxo ácrico de Ribeirão Preto - LRác1 (C = caulinita; $\mathbf{G b}=$ gibbsita; VHE = vermiculita com hidroxila entrecamadas).

Os resultados foram semelhantes aos obtidos por GALHEGO \& ESPINDOLA (1979), CURI \& FRANZMEIER (1984) e ANTONELLO (1988). A caulinita, com picos a 0,72 e 0,36 nm, e curvas de reação endotérmica a $530^{\circ} \mathrm{C}$, juntamente com a gibbsita, com difrações a 0,48 e 0,44 nm, e reação endotérmica a $290^{\circ} \mathrm{C}$ foram os minerais dominantes, aparecendo em todas as amostras. Anatásio apareceu no LRác2 (figura 2) e no LUác (figura 3), mesmo após o aquecimento a $550^{\circ} \mathrm{C}$, quando o pico de $0,35 \mathrm{~nm}$ esteve presente. Este óxido de titânio não sofre ataque do ditionito e extremamente resistente a tratamentos térmicos, ao contrário de alguns minerais de argila.

Aquecimentos a 350 e $550^{\circ} \mathrm{C}$ resultaram em colapso parcial, indicando a presença de vermiculita com hidroxila entrecamadas - VHE (figuras 1 e 2). 0 aparecimento de minerais interestratificados em solos altamente intemperizados $\mathrm{j} 6$ foi assinalado por MOURA FILHO \& BUOL (1972) e GALHEGO \& ESPINDOLA (1979). As pequenas quantidades destes minerais pareceram não a fetar os atributos eletroquímicos dos solos estudados, visto que os valores de densidade de carga elétrica e CTC foram baixos, mesmo na presença de traços de VHE (ALLEONI \& CAMARGO, 1994 b). SKJEMSTAD \& KOPPI (1983) haviam feito a mesma constatação

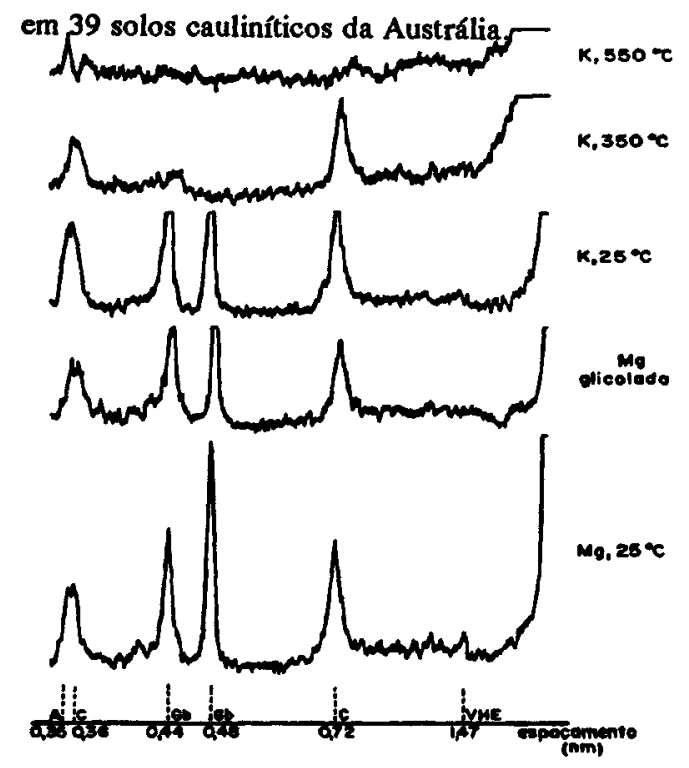

Figura 2 - Difratogramas de raios $X$ da fração argila deferrificada de horizonte $B$ do latossolo roxo ácrico de Guaíra -LRác2 (C = caulinita; $G \mathrm{~b}=$ gibbsita; $\mathbf{A}=$ atanásio; $\mathrm{VHE}=$ vermiculita com hidroxila entrecamadas).

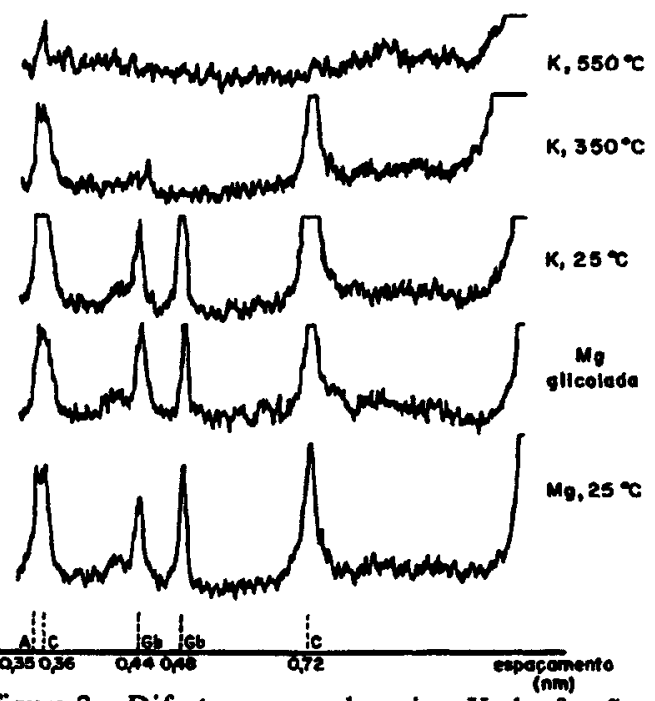

Figura 3 - Difratogramas de raios $X$ da fração argila deferrificada de horizonte $B$ do latossolo variação Una ácrico - LUác (C = caulinita; $\mathbf{G b}=$ gibbsita; $A=$ atanásio). 


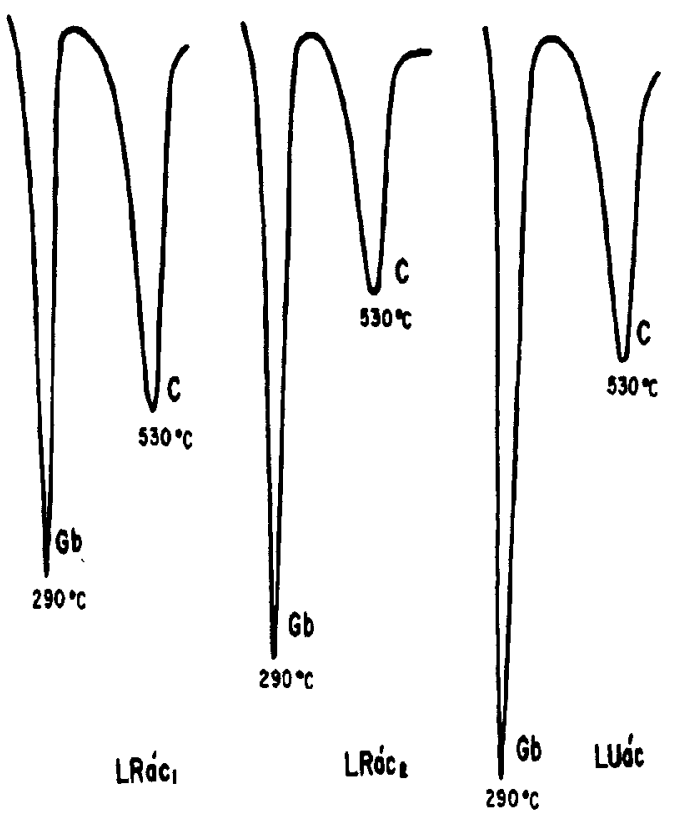

Figura 4 - Curvas de análise térmica diferencial das frações de argila, livres de ferro e saturadas com $\mathrm{Mg}$, do horizonte $B$ de latossolos ácricos (LRác1 e LRác2 = latossolos roxos ácricos de Ribeirão Preto e Guaíra, respectivamente; LUác = latossolo variação Una ácrico; $\mathrm{C}=$ caulinita e $\mathrm{Gb}=$ gibbsita).

As porcentagens de caulinita e gibbsita foram calculadas a partir das áreas das curvas de ATD (figura 4). Nos latossolos roxos, a gibbsita respondeu por metade ou mais da fração argila deferrificada $(500 \mathrm{~g} / \mathrm{kg}$ para o LRác1 e $640 \mathrm{~g} / \mathrm{kg}$ para o LRác2). No LUác, a caulinita prevaleceu $(540 \mathrm{~g} / \mathrm{kg})$. Como explicam CURI \& FRANZMEIER (1984) e OLIVEIRA et al. (1991), a quantidade de gibbsita tende a ser maior nos solos mais vermelhos, enquanto a caulinita segue tendência contrária.

\section{CONCLUSÕES}

- Os teores totais e também os livres e os amorfos de ferro e alumínio, além da porcentagem da gibbsita, em relação à caulinita, foram maiores nos latossolos roxos ácricos do que no latossolo variação Una ácrico.
- A mineralogia da fração argila deferrificada dos horizontes Bw foi dominada por caulinita e gibbsita, mostrando o avançado estado de intemperismo dos solos ácricos. Nos difratogramas de raios $\mathrm{X}$ apareceram também picos de vermiculita com hidroxila entrecamadas (VHE).

- O latossolo variação Una, de coloração amarelada, localizado nas cotas mais inferiores do terreno, teve uma relação superfície específica / Fe livre maior do que as relações dos latossolos roxos, que localizam-se normalmente nas cotas mais altas da topossequiência.

\section{REFERÊNCIAS BIBLIOGRÁFICAS}

ALLEONI, L.R.F.; CAMARGO, O.A. Pontos de efeito salino nulo de latossolos ácricos. Revista Brasileira de Ciéncia do Solo, v.18, n.2, p.175-80, 1994a.

ALLEONI, L.R.F.; CAMARGO, O.A. Potencial elétrico superficial e carga elétrica líquida de latossolos ácricos. Revista Brasileira de Ciência do Solo, v.18, n.2, p.181-5, $1994 b$.

ALLEONI, L.R.F.; CAMARGO, O.A. Atributos físicos de latossolos ácricos do norte paulista. Scientia Agricola, v.51, n.2, p.321-6, $1994 \mathrm{c}$.

ANTONELLO, L.L. Mineralogy of the deferrified clay fraction in B horizon of pedons of the VIIIth International Soil Classification Workshop. In: INTERNATIONAL SOIL CLASSIFICATION WORKSHOP, 8 , Rio de Janeiro, 1986. Proceedings. Rio de Janeiro: EMBRAPA/SNLCS, 1988. p.109-38.

CURI, N.; FRANZMEIER, D.P. Topossequence of Oxisols from the Central Plateau of Brazil. Soil Science Society of America Journal, v.48, p.341-6, 1984.

ESWARAN, H.; TAVERNIER, R. Classification and genesis of Oxisols. In: THENG, B.K.G., ed. Soils with variable charge. Palmerston North: Offset Publications, 1980. p.427-42.

GALHEGO, H.R.; ESPINDOLA, C.R. Mineralogia da argila de solos desenvolvidos de produtos de alteração de rochas eruptivas básicas em Botucatu - SP. Revista Brasileira de Ciência do Solo, v.3, n.2, p.131-5, 1979.

KÄMPF, N.; REZENDE, M.; CURI, N. Iron oxides in Brazilian Oxisols. In: INTERNATIONAL SOIL CLASSIFICATION WORKSHOP, 8., Rio de Janeiro, 1986. Proceedings. Rio de Janeiro: EMBRAPA/ SNLCS, 1988. p.71-7. 
MELO, M.E.C.C.M.; JOHAS, R.A.L. Teores de ferro, na terma fina e na argila, por ataque sulfúrico e triácido e extração pelo CDB. In: REUNIÃO DE CLASSIFICAÇÃO, CORRELAÇÃO DE SOLOS E INTERPRETAÇÃO DE APTIDẨO AGRfCOLA, 3., Rio de Janeiro, 1988. Angis. Rio de Janeiro, EMBRAPA/ NLCS, 1988. p.211-3 (Documentos EMBRAPA/ SNLCS, 12).

MOURA FILHO, W.; BUOL, S.W. Studies of Latossol Roxo (Eutrustox) in Brazil : Clay mineralogy. Experimentae, n.13, p.201-17, 1972.

NASCIMENTO, R.A.M.; CUNHA, L.H.; RAMOS, D.P. Comparação entre o ponto de carga zero (titulação potenciométrica), mineralogia e diversos outros parâmetros, para quatorze perfis de latossolos. In: REUNIÃO DE CLASSIFICAÇĀO, CORRELA-ÇĀO DE SOLOS E INTERPRETAÇÃO DE APTI-DÃO AGRf́COLA, 3., Rio de Janeiro, 1988. Angis. Rio de Janeiro, EMBRAPA/SNLCS, 1988 . p.365-90. (Documentos EMBRAPA/SNLCS, 12).

OLIVERA, J.B.; PRADO, H. Lerantamento pedol6gico semi-detalhado do Estado de Sáo Paulo: quadrícula de Ribeirão Preto; II. Memorial descritivo. Campinas: Instituto Agronómico, 1987. 133p. (Boletim Científico, 7).

OLIVERA, J.B.; PRADO, H. Levantamento pedológico semi-detalhado do Dstado de Sxa Paulo: quadrícula de Guaira. Campinas: Instituto Agronômico, 1994 (no prelo).

OLIVEIRA, J.B.; REZENDE, M.; CURI, N.Caracterização e classificação de latossolos variação Una e de solos afins da região de Guaíra, SP. Revista Brasileira de Ciencia do Solo, v.15, n.2, p.207-18, 1991.
POMBO, L.C.A.; KLAMT, E.; KUNRATH, I.; GIANLUPPI, D.I. Identificação de 6xidos de ferro na fração argila de latossolo roxo. Revista Brasileira de Ciencia do Solo, v.6, n.1, p.13-7, 1982.

SAKURAI, K.; OHDATE, Y.; KYUMA, K. Factorsaffecting zero point of charge (ZPC) of variable charge soils. Soil Science and Fiant Nutrition, v.35, n.1, p.21-31, 1989.

SKJEMSTAD, J.O.; KOPPI, A.J. Chemical and charge characteristics of kaolinite soils of South-east Queensland. Australian Journal of Soil Research, v.21, p.271-83, 1983.

VIRGNIA POLITECHNIC INSTITUTE AND STATE UNIVERSITY. Keys to soil taxonomy. $4 \mathrm{ed}$. Blacksburg, 1990. 423p. (USDA/SMSS, Technical Monograph, 6).

UEHARA, G. Acric properties and their significance to soil classification. In: INTERNATIONAL SOIL CLASSIFICATION WORKSHOP, 8., Rio de Janeiro, 1986. Proceedings. Rio de Janeino: EMBRAPAI SNLCS, 1988. p.19-22.

VETTORI, L. Metodos de análise de solos. Rio de Janeiro: Ministério de Agricultura, 1969. 24p. (Boletim técnico, 7 ).

Entregue para publicação em 09.01.95

Aceito para publicação em 03.03 .95 